\title{
A implementação do sistema de custos proposto pelo governo federal: uma análise sob a ótica institucional
}

\author{
Thiago Bernardo Borges \\ Instituto Brasileiro de Mercado de Capitais \\ Poueri do Carmo Mario \\ Universidade Federal de Minas Gerais \\ Ricardo Carneiro \\ Escola de Governo Professor Paulo Neves de Carvalho da Fundação João Pinheiro
}

As informações sobre custos no setor público são importantes para uma análise adequada de eficiência e qualidade do gasto. Em países de referência a implementação dessa metodologia teve caráter mais abrangente, não focado apenas em questões técnicas. A teoria institucional discute justamente a necessidade de que tais transformações no cotidiano dos servidores devem envolver ajustes das normas, valores e práticas em uso nas organizações envolvidas. Neste contexto é que se insere este trabalho, que procurou através da ótica institucional, e comparando com o processo de reforma australiano, analisar como se desenvolveu no governo federal brasileiro a incorporação de novas ferramentas de gestão. Assim, identificou-se, diferentemente do que sugere a teoria institucional e a experiência internacional, que o governo brasileiro optou pela implantação de uma solução tecnológica, em detrimento de uma mobilização institucional mais ampla.

Palavras-chave: contabilidade pública; Nova Gestão Pública; sistemas de custo; institucionalismo.

\begin{abstract}
Aplicación del sistema de gastos del gobierno federal: un análisis según una lente institucional

La información sobre los costos en el sector público son importantes para un correcto análisis de la eficiencia y calidad del gasto. En referencia a los países que aplican esta metodología tuvo un enfoque más extenso, no sólo se centró en cuestiones técnicas. La teoría institucional argumenta sobre la necesidad de tales transformaciones en las situaciones cotidianas de lós servidores debe implicar ajustes de las normas, los valores y las prácticas en uso en las organizaciones. En este contexto, En este contexto, es que este trabajo se ajusta a esa búsqueda a través de la lente institucional, y comparando con el proceso de reforma del gobierno de Australia, analizar cómo se desarrolló en el gobierno federal brasileño la incorporación de nuevas herramientas de gestión. Por lo tanto, fue identificado de forma diferente
\end{abstract}

Artigo recebido em 21 nov. 2011 e aceito em 10 dez. 2012. 
que sugiere la teoría institucional y la experiencia internacional, que el gobierno brasileño optó por implementar una solución tecnológica, en lugar de una movilización institucional más amplia.

Palabras claves: contabilidad pública; Nueva Gestión Pública; sistemas de costeo; institucionalismo.

Implementing costs systems proposed by federal government: an analysis under a institutional lens

The information about costs in public sector is important to an adequate analyze about management efficiency and expenditure quality. In countries identified as reference for implementation of that methodology, the process was part of a extensive reforms plan. The Institutional Theory claim the importance that changes in those work proceedings need analyze rules, values and practices in use on the organization involved in change process. This study was intended using the institutional theory to establish an analyze of how was the implementation of public sector Brazilian management instruments, and comparing that same process in Australian government. It was possible identified that Brazilian government different of the international experience and institutional theory proposals that suggest a wide cultural and institutional mobilization, it chose only the implementation of a technological system.

Key words: public accounting; New Public Management; cost systems; institutionalism.

\section{Introdução}

A criação do Ministério da Administração e Reforma do Estado (Mare), ${ }^{1}$ em 1995, no governo Fernando Henrique Cardoso, marca formalmente a adesão do Brasil ao movimento de reformas gerenciais designado Nova Administração Pública (ou New Public Management). Tal movimento propugna um modelo de gestão orientada para resultados, que enfatiza a eficiência, envolvendo, entre outras iniciativas, a descentralização dos controles gerenciais no sentido de maior autonomia, responsabilização e flexibilização de procedimentos, a introdução de mecanismos de mercado na gestão pública, uma distinção mais específica entre formulação e implementação de políticas públicas e a maior transparência na realização do gasto (Rezende, 2002).

Essa mudança de visão sobre a gestão da coisa pública vem ancorada nas discussões que ganharam força a partir da crise que acomete as principais economias capitalistas ao longo da década de 1970. Na visão que iria se tornar hegemônica à época, os problemas defrontados pelo capitalismo são percebidos como excesso de intervencionismo estatal, num diagnóstico que desemboca no argumento de que o modelo burocrático de gestão se revela ineficiente na administração dos recursos públicos e no atendimento das necessidades e demandas da sociedade. Em consonância com esse diagnóstico, a solução proposta, segundo Bresser-Pereira (1998:39), seria a reconstrução do Estado, entendida como:

\footnotetext{
${ }^{1}$ O Ministério da Administração e Reforma do Estado foi extinto em 1999, início do segundo mandato do presidente Fernando Henrique Cardoso.
} 
(...) recuperação da poupança pública e superação da crise fiscal; redefinição das formas de intervenção no econômico e no social por meio da contratação de organizações públicas não estatais para executar os serviços de educação, saúde, e cultura; e reforma da administração pública com a implantação de uma administração pública gerencial.

Segundo Boland e Fowler (2000), a implementação da agenda de reformas de cunho gerencialista impõe a necessidade do desenvolvimento de indicadores de desempenho. Francesco (1999:421) acrescenta que tais indicadores têm a finalidade de alinhar as políticas prioritárias dos governos com as demandas da sociedade. Dessa forma, o sistema de controle da gestão muda de foco, deixando de se basear estritamente nos processos para se concentrar nos resultados (Franco, 2004).

Políticas contábeis e financeiras, conforme Warren e Barnes (2003:8), impactam na performance organizacional do governo como um todo. Os autores argumentam que um bom desempenho econômico e organizacional depende de decisões melhores e, para que isto aconteça, deve existir um bom mecanismo para medir os resultados. Neste contexto, a contabilidade é pressionada a exercer seu papel de prover seus usuários com demonstrações e análises de natureza econômica, financeira, física e de produtividade, com relação à entidade objeto de contabilização (Iudícibus e Marion, 2001).

Para Hodgkinson (1999:472), um indicador de desempenho fundamental é o de produtividade, definido como uma medida física expressa em uma razão entre produtos e insumos. O autor acrescenta que, presente na definição de insumo, está o conceito de custo, o qual, segundo Martins (2006:25), é a medida de todo o gasto relativo a bens ou serviços utilizados na produção de outros bens ou serviços. A informação sobre os custos do setor público é tão importante que, para Alonso (1999:39), sua ausência representa o maior grau de ineficiência na aplicação dos recursos públicos. Rezende, Cunha e Bevilacqua (2010:962) acrescentam que as informações de custo são imprescindíveis para a apuração das relações entre recursos efetivamente utilizados, os produtos entregues à sociedade e os benefícios decorrentes dos produtos. A mensuração e o controle dos custos na gestão pública, para Machado e Holanda (2010:792), integram uma das etapas essenciais para a transformação de paradigmas atualmente existentes sobre o papel e a importância do setor público como agentes propulsores de geração de eficiência no uso de recursos públicos e também escassos.

Assim, pautados em uma visão gerencial, entes estatais de diversos países têm procurado adotar metodologias de custeio para obter informações sobre custos das políticas e serviços públicos. É o que fez, entre outros, a Austrália — país que constitui referência recorrente no tocante à adoção de reformas gerenciais na administração pública. Mais recentemente, o Brasil também avançou nessa direção, o que se materializou na proposição de um sistema de custos para os órgãos da administração pública federal, denominado Sistema de Informação de Custos (SIC). No entanto, diferentemente do caso australiano, onde as inovações no campo contábil e financeiro se inscrevem num processo mais amplo e articulado de reforma administrativa, que obteve êxito na difusão e legitimação da cultura gerencial, a iniciativa brasileira não se atrela a um planejamento de longo prazo, descurando-se de uma mobilização inclusiva da burocracia. 
Como sinaliza o aporte teórico da análise institucional, a implementação do SIC, contudo, nada tem de trivial, na medida em que não se esgota na mera alteração na legislação setorial. De fato, mudanças institucionais de maior envergadura, como a pretendida pelo governo brasileiro, não se coadunam, necessariamente, com normas, valores e práticas em uso nas organizações envolvidas no processo, o que tende a dificultar e, no extremo, inviabilizar sua efetiva adoção. Indo direto ao ponto, o sucesso de tal iniciativa, que é afinada com o gerencialismo, supõe a difusão do discurso gerencialista no aparato estatal, para que o mesmo se sobreponha aos padrões já identificados pela burocracia como concepções legítimas da maneira eficaz de gestão da coisa pública. Na visão dos gestores responsáveis pelo processo de implementação (Holanda, Lattman-Weltman e Guimarães, 2010:106), a utilização do SIC, mesmo que inicialmente precária, deve funcionar como um dinamizador para a mudança cultural necessária à sua assimilação pelos órgãos da administração federal.

O artigo aborda a iniciativa de implementação do novo sistema de custo pelo governo brasileiro, examinando-a sob a ótica da teoria institucional. Trata-se de uma abordagem descritiva, entendida como aquela que busca apresentar melhor as características de determinado fenômeno, estabelecendo relações entre as variáveis relevantes à sua conformação (Martins e Theophilo, 2007). Além disso, dada a fase exploratória que reveste a discussão do tema no Brasil, recorre-se à experiência australiana, antes mencionada, com o intuito de levantar pontos relevantes ao exame da questão.

Este artigo, além desta introdução, expõe pontos importantes da teoria institucional e algumas discussões acerca da estabilidade dos sistemas gerenciais. Na sequência, apresenta as experiências de reforma gerencial dos governos australiano e brasileiro, enfatizando aspectos relacionados à gestão financeira e contábil. Por fim, tece algumas considerações acerca das perspectivas de êxito da iniciativa brasileira, destacando a importância da dimensão cultural de empreendimentos reformistas de maior envergadura.

\section{Teoria institucional e a contabilidade gerencial}

O contexto organizacional do corrente século é marcado por acelerados avanços nas tecnologias de informação e pela intensificação da globalização dos mercados, impulsionando a adoção de novas técnicas gerenciais, gerando mais demanda da contabilidade e maior acurácia de seus instrumentos e técnicas. Segundo Burns e Scapens (2000:3), os gerentes têm se valido dos sistemas contábeis e de relatórios financeiros com maior flexibilidade, utilizando estas informações juntamente com outros indicadores de desempenho, financeiros ou não.

A forma como ocorre o processo de mudança das práticas e sistemas contábeis encontra, na análise institucional, subsídios valiosos à sua interpretação.

Diferentemente da visão dos indivíduos como agentes racionais, plenamente informados e orientados para a busca de soluções ótimas, que tipifica a teoria da escolha racional consagrada pela economia neoclássica, a análise institucional admite que os indivíduos possuam racionalidade limitada, valendo-se de regras, pressupostos e experiências para interpretarem o mundo e tomarem uma decisão (North, 1990:4). Essa perspectiva analítica pode ser en- 
contrada na vertente interpretativa da denominada Old Institutional Economics (OIE), que proporciona fundamentos teóricos para a compreensão da rotina organizacional e sua institucionalização. Para a OIE, é praticamente impossível, no mundo real, um indivíduo realizar análises exaustivas para tomada de decisão, como preconizado pelo modelo interpretativo da escolha racional. Dessa forma, hábitos e rotinas revelam-se muito úteis ao encaminhamento do processo decisório.

Não existe uma definição amplamente aceita para o termo instituição. A amplitude de significados leva autores como Powell e DiMaggio (1991) a afirmarem que é mais fácil obter acordo sobre o que instituição não é do que sobre o que é. Passando ao largo da ambiguidade conceitual, para os teóricos da OIE o termo é definido, conforme Burns e Scapens (2000:5), como "modo de pensar ou agir contínuo e prevalecente, o qual está intrínseco nos hábitos de um grupo ou de uma comunidade". Os autores acrescentam que instituições podem ser consideradas uma imposição de forma e coerência social às atividades humanas, por meio da produção e reprodução de pensamentos e ações já consolidados ou que se tornaram rotina. Já rotina é entendida como um padrão habitualmente adotado por um grupo de indivíduos. De acordo com a literatura institucional, para que uma rotina em uma organização seja estabelecida, é preciso existir um grupo de regras de comportamento, sejam elas explícitas em manuais ou não. Uma vez que a rotina foi estabelecida na organização, é o grupo que vai analisar se é viável alguma modificação na mesma.

Segundo Guerreiro e colaboradores (2005:99), as rotinas dão coesão ao "sistema empresa" (Giddens, 1984). Os autores sintetizam as principais características de uma instituição, na relação estabelecida com a organização, da forma apresentada no quadro 1.

Quadro 1

Principais características de uma instituição

\begin{tabular}{|ll|}
\hline \multicolumn{1}{|c|}{ Característica } & \multicolumn{1}{c|}{ Descrição } \\
\hline Caráter coletivo & $\begin{array}{l}\text { As instituições são estruturadas por meio de rotinas definidas por pensamentos e hábitos } \\
\text { formalizados e aceitos por pessoas de um determinado grupo social. }\end{array}$ \\
$\begin{array}{ll}\text { Caráter de dar significado ao com- } \\
\text { portamento organizacional }\end{array}$ & $\begin{array}{l}\text { As instituições permitem aos indivíduos e grupos dentro da organização dar significado às } \\
\text { suas atividades do dia a dia. }\end{array}$ \\
Caráter objetivo & As instituições definem padrões de comportamento que são esperados de um determinado \\
& grupo social. \\
Caráter de não questionamento & As instituições geralmente espelham regras estabelecidas para a organização, porém isso \\
Caráter repetitivo & nem sempre ocorre. Existem regras que não são aceitas pelo grupo social. \\
Caráter de estabilidade & A instituição implica hábito, rotina e, portanto, repetição de ações. \\
& O período de tempo em que perduram as instituições é bastante variável. Existem institui- \\
& ções que possuem uma vida curta e outras, uma vida mais longa. Porém todas têm certo \\
& período de tempo em que são prevalecentes e, durante esse período de tempo, existe \\
estabilidade. & Quanto mais ampla e profundamente uma instituição é aceita, mais provável é sua influência \\
Caráter de orientar ações & no sentido de direcionar ações e resistir a mudanças. \\
\hline
\end{tabular}

Fonte: adaptado de Guerreiro e colaboradores (2005). 
No contexto da contabilidade gerencial, e principalmente na contabilidade pública, as regras estabelecem o sistema contábil e se encontram formalizadas nos manuais de procedimento, enquanto as rotinas são as práticas contábeis realmente em uso. Segundo Burns e Scapens (2000:5), existe um relacionamento entre as regras e as rotinas, mas não se pode confundir as duas, pois as práticas não necessariamente obedecem aos ditames dos manuais. As práticas da contabilidade gerencial modelam e são modeladas pelas instituições, as quais governam a atividade organizacional.

Para as organizações, a contabilidade representa um "conjunto fortemente estruturado de rotinas" (Guerreiro et al., 2005:100), que permite a elaboração de orçamentos, a análise de desempenho, a produção regular de relatórios etc. A contabilidade estabelece uma estrutura fundamental para que os eventos econômicos sejam apresentados e representados para os membros da organização, além de definir os direitos desses membros e informar a tomada de decisão (Guerreiro et al., 2005).

Sob um olhar mais amplo, as práticas da contabilidade gerencial proporcionam coerência social bem como significado ao comportamento organizacional, ao garantir significados às atividades diárias dos membros da organização. Nas palavras de Guerreiro e colaboradores (2005:101):

Quando as práticas contábeis tornam-se rotinas institucionalizadas, seus papéis no processo organizacional e na tomada de decisão são totalmente aceitos pelos membros da organização. A contabilidade, dessa forma, torna-se um mecanismo que dá sentido às atividades empresariais e que intervém como mediadora de potenciais conflitos dentro da organização.

Contudo, é importante destacar que a institucionalização mencionada por Guerreiro e colaboradores $(2005: 101)$ pode ser dificultada por fatores como a contabilidade não ser a forma dominante de controle organizacional ou a existência de conflitos e resistências em torno da introdução de novos sistemas contábeis para controle. Assim, para qualquer ambiente, é necessário se ter em mente o relacionamento das práticas contábeis adotadas com as outras rotinas da organização.

Guerreiro e colaboradores (2005) afirmam que, apesar da existência de um novo ferramental na contabilidade gerencial, capaz de possibilitar o desenvolvimento de indicadores mais refinados, permitindo maior eficiência na alocação de recursos, observa-se que muitas empresas ainda estão ativamente empenhadas na introdução de sistemas contábeis considerados tradicionais. Sob a ótica institucional, tal fato ocorre porque as inovações não estão em linha com as expectativas dos indivíduos ou em conformidade com as normas sociais de comportamento aceitável na empresa.

Ainda de acordo com Guerreiro e colaboradores (2005:102), a introdução de um novo modelo traz insegurança, riscos e questionamentos da competência dos indivíduos em lidar com novas variáveis, deslocando o eixo de poder. A tomada de decisão sobre eventos econômicos nas organizações, em muitos casos, segue um modelo repetitivo, o que permite uma antecipação dos resultados e, consequentemente, de sua avaliação. Retirar essa estabi- 
lidade obriga os indivíduos a agirem de forma diferente; assim, surge a incerteza de como serão cobrados e avaliados. Os autores argumentam que é necessária a integração de diversos fatores para que uma mudança de sistema contábil seja adequadamente institucionalizada, quais sejam: (a) que exista uma orientação normativa no sentido de implementação do novo modelo; (b) que o novo modelo seja efetivamente compreendido pelas pessoas; (c) que existam elementos facilitadores para o processo de repetição do modelo proporcionando certa estabilidade e gerando hábitos; (d) que as pessoas percebam claramente as consequências da implantação do modelo no plano pessoal; (e) que a implementação do novo modelo confira legitimidade para as pessoas; (f) que o novo modelo represente efetivamente como os indivíduos serão avaliados não só institucionalmente, mas também subjetivamente pelos seus pares; (g) que o novo modelo esteja sintonizado com as crenças e os valores aceitos pelos membros da organização.

Em suma, o que se pode perceber, adotando-se a perspectiva analítica institucional, é que uma mudança nos padrões contábeis de uma organização não expressa uma decisão estritamente técnica. Ao contrário, tal mudança mobiliza vários recursos organizacionais de natureza institucional. Sendo mais explícito, a dimensão técnica acaba relegada ao segundo plano. O impacto na rotina dos indivíduos e o convencimento da relevância da nova informação gerada são os elementos de maior relevância. A preocupação com esses aspectos pode ser percebida no encaminhamento das ações da reforma empreendida na Austrália, brevemente descritas a seguir.

\section{Contexto e reforma gerencial na Austrália}

Com as discussões sobre o novo gerencialismo estatal ganhando força no contexto internacional a partir da década de 1970, segundo Guthrie (1998), o governo central australiano deu início a uma série de reformas administrativas com o intuito de elevar a eficiência, efetividade, responsabilização e transparência das atividades públicas.

Warren e Barnes (2003) destacam que os organizadores das reformas gerenciais na administração pública compreendiam o impacto da provisão de boas informações para auxiliar os gestores na correta determinação das diretrizes organizacionais. Argumentam que tais escolhas, somadas a mecanismos de coordenação e incentivo, são capazes de influenciar a performance da economia como um todo.

Warren e Barnes (2003) acrescentam que um bom mecanismo de transparência e de fluxo de informações é determinado pela natureza e relacionamento entre a especificação de desempenho, delegação da autoridade para decisões, incentivos aos agentes e relatórios de desempenho atrelados à especificação determinada. Como pano de fundo tem-se a alta qualidade da informação. Ou seja, é necessário o envolvimento da alta gerência na compreensão dos processos de trabalho, na definição das metas e na cobrança dos resultados, e esse monitoramento ocorrerá através dos relatórios de desempenho. O funcionamento desse fluxo de informações gera incentivo para que os gestores de nível médio exijam a correta inserção de 
dados nos sistemas, além de impedir que os relatórios sejam arquivados sem utilização. Todo o processo de gestão australiano está ancorado nesta lógica.

Warren e Barnes (2003) afirmam que a qualidade dos relatórios financeiros externos reflete a qualidade das políticas contábeis adotadas e a confiança sobre a fidedignidade das informações produzidas.

O programa de melhoramento da gerência financeira foi um guarda-chuva sob o qual diversas reformas foram realizadas, entre elas, destacam-se: (a) custos correntes; (b) programa gerencial e orçamentário; (c) terceirização de serviços; e (d) planejamento corporativo.

As reformas impactaram a forma de comercialização e contratação dos órgãos públicos, que passaram a utilizar uma nova gama de informações para auxiliar seus gerentes, tais como controle de custos de serviços e bens, contingenciamento de despesas, administração de ativos, avaliação de contratos e outros. Assim, com o passar do tempo o foco da administração pública australiana deslocou-se para o controle de custos e despesas, bem como para a análise de desempenho financeiro e de resultado dos programas e entidades governamentais.

As primeiras fases da reforma exigiram que o governo constituísse um plano compreensível e atingível de objetivos estratégicos a serem alcançados. Em seguida os objetivos deveriam ser desdobrados em metas bem próximas da realidade dos funcionários públicos. Além disso, uma metodologia de incentivos foi criada para manter o alinhamento estratégico de toda a organização ao longo do tempo, juntamente com uma estrutura que permitisse o fluxo de informações qualificadas entre a base da organização e a alta gestão do governo (Guthrie, 1998).

De acordo com Rezende, Cunha e Bevilacqua (2010:967):

Nova Zelândia e Austrália, que lideraram as iniciativas de adotar o orçamento de competência, o fizeram no bojo de uma ampla reforma fiscal, que agregou, às demandas da macroeconomia por responsabilidade fiscal, a adoção de um novo regime orçamentário. Nessas reformas, os órgãos públicos que cuidam da gestão das políticas e programas governamentais ganharam autonomia para gerir os recursos a elas atribuídos em troca de compromissos com o alcance de metas de resultados, que são oficialmente estabelecidas e contratadas. Esse modelo estimula a competição entre as entidades públicas e tem como referência procedimentos de gestão semelhantes aos adotados pela iniciativa privada, que pode, inclusive, assumir a gestão de serviços públicos mediante um mandato específico.

Dentro da estrutura de informação é que se encaixa a reforma financeira ocorrida na Austrália. Assim, as organizações ligadas à contabilidade - Australian Accounting Research Foundation, Australian Accounting Standards Board e Public Sector Accounting Standards Board - , em conjunto com o Poder Legislativo, defendiam a adoção do regime de competência para o setor privado e público. Com esse propósito, foi elaborado o documento intitulado Proposta Geral de Demonstrações Financeiras (PGDF).

Em 1994, uma norma exigiu a preparação da PGDF. No mesmo ano, o departamento de finanças do governo central propôs que essa instrução contábil fosse adotada por todo o governo. A PGDF foi desenvolvida em quatro eixos essenciais, a saber: Relatórios Financeiros, 
Sistema de Gerenciamento Contábil, Relatório Geral do Governo e Planejamento Orçamentário baseado no regime de competência, os quais procuravam promover seu fortalecimento.

Quadro 2

Eixos de fortalecimento da Proposta Geral de Demonstrações Financeiras

\begin{tabular}{|ll|}
\hline Categorias & Descrição \\
\hline Relatórios Financeiros & $\begin{array}{l}\text { Têm periodicidade anual e congregam demonstrações baseadas no regime de compe- } \\
\text { tência puro. Compreendem as demonstrações operacionais, execução de programas, } \\
\text { demonstrações patrimoniais, demonstração de fluxo de caixa, demonstração das } \\
\text { variações nos fundos, além das notas explicativas e certificados do chefe do Executivo } \\
\text { e do auditor geral. }\end{array}$ \\
Sistemas de Gerenciamento Contábil & $\begin{array}{l}\text { Envolvem os sistemas de informações internos necessários para criar e registrar infor- } \\
\text { mações sobre receitas, despesas, ativos e passivos. }\end{array}$ \\
Relatório Geral do Governo & $\begin{array}{l}\text { Refere-se à visão da posição financeira de todo o governo. É preparado via consolidação } \\
\text { de todas as demonstrações e transações realizadas no sistema governamental. }\end{array}$ \\
Planejamento Orçamentário & $\begin{array}{l}\text { Passou a ser baseado no regime de competência, e não mais sob o regime de caixa, } \\
\text { implicando a inclusão de custos como depreciação e designação de novos funcioná- } \\
\text { rios. A mudança resulta em ênfase na alocação de recursos com base em números de } \\
\text { acordo com a competência e não na movimentação monetária. }\end{array}$ \\
\hline
\end{tabular}

Fonte: adaptado de Guthrie (1998:2).

A produção dos relatórios designados na PGDF permitiu a elaboração de diversos indicadores de desempenho. Contudo, todos tiveram de ser adaptados para utilização no setor público, uma vez que a natureza desses indicadores se prende originalmente ao atendimento de demandas do setor privado.

A introdução de novas tecnologias trouxe a necessidade de mudança da cultura organizacional, no sentido de como produzir as informações requeridas. Além disso, tornou-se importante o investimento em treinamento e desenvolvimento de novas habilidades dos funcionários e principalmente dos gestores. Um argumento a favor dos dispêndios com adoção de novos sistemas de informação baseados no regime de competência é que eles irão permitir o reconhecimento dos custos totais de serviços.

Com o passar dos anos, o modelo foi sendo aperfeiçoado e, de acordo com Carlin (2003:7), no final da década de 1990 todo o setor público australiano já havia adotado o regime de competência e o sistema de relatórios financeiros sob esta base. A implementação do regime de competência puro se deu em etapas, devido à necessidade de adoção de diversas reformas no sistema financeiro do setor público.

Sob esse ponto de vista, as mudanças na administração financeira do setor público australiano, conforme Carlin (2003), podem ser classificadas em três categorias: precursoras, centrais e resultantes, esquematizadas na figura 1. 
Figura 1

Fases de implementação do regime de competência puro

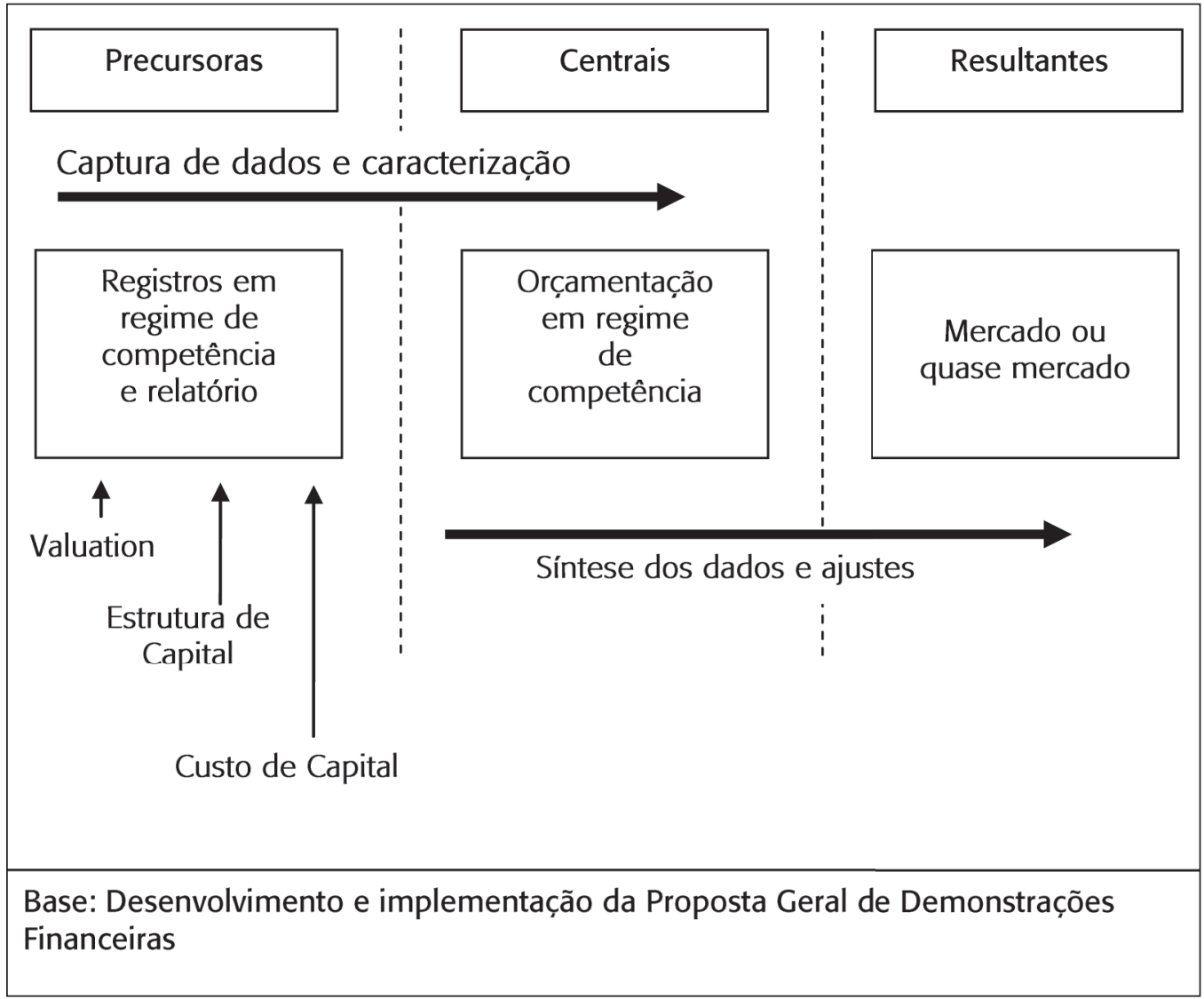

Fonte: Adaptado de Carlin (2003:26).

As mudanças precursoras envolvem a adoção de algumas técnicas que são precondições necessárias para a subsequente implementação de outras. Registros e relatórios em regime de competência encaixam nessa categoria.

A base legal de registros e relatórios entra como um mecanismo de alimentação para a segunda categoria, nomeada central. A técnica de orçamentação baseada no regime de competência encontra-se como o centro do novo ambiente de administração financeira no setor público, sendo caracterizada pela criação de medidas físicas e financeiras para todos os produtos dos órgãos públicos.

As implicações dos novos cálculos financeiros são profundas. Desde que a administração pública passou a analisar suas escolhas como as de aquisição de produtos de acordo com os resultados a serem atingidos, o lócus de produção tornou-se indiferente. Então as reformas centrais, tendo alterado a perspectiva sobre os produtos dos órgãos, definindo-os com base 
nos custos de cada função, transmitiram esses dados para a terceira categoria, ou resultante, onde os produtos são negociados na busca de uma disponibilização mais eficiente (Carlin, 2003:26).

Carlin (2003) ainda acrescenta que nem as reformas centrais, nem as reformas de mercado ou quase mercado para produtos podem funcionar sem os dados do sistema alimentador que, no caso, são os relatórios e registros da contabilidade. Por essa razão, os custos dos produtos calculados dentro da orçamentação com base no regime de competência e transmitido para os mercados serão sensíveis aos pressupostos adotados pelo sistema de contabilidade.

Estudiosos orientados por uma corrente gerencial, Guthrie, Olson e Humphrey (1999:211) defendem que a administração financeira na Austrália não está mais limitada aos departamentos de finanças ou do tesouro e que o conceito de usuário da contabilidade não está restrito aos profissionais de contabilidade. Segundo os autores, gerentes, prestadores de serviços, representantes políticos e o público em geral em variados graus entendem que a informação contábil é importante para preparar, registrar, responder, interpretar e gerenciar as políticas públicas, sendo a linguagem contábil/financeira a que crescentemente torna-se o padrão informacional.

Estudo de Hoque (2008), Mir e Rahaman (2007) e Hoque e Adams (2011) apresentam exemplos de instituições públicas australianas que ao longo de 20 anos estão em processo de institucionalização das propostas da Nova Administração Pública e do modelo de gestão para resultados. Os estudos destacam a incorporação de ferramentas do setor privado e também a utilização pelos gestores dessas instituições de relatórios gerenciais de desempenho. Os autores afirmam que não se pode dizer que haja uma aplicação generalizada e nem mesmo uniforme, mas é possível comprovar que o ideário de uma alocação de recursos mais eficiente, com análises de custos de produtos e serviços confrontados com as metas estabelecidas, já está presente no dia a dia do setor público. Bem como a disponibilização de relatórios internos e externos para a tomada de decisão (Hoque, 2008; Hoque e Adams, 2011).

Também é possível destacar a utilização da informação gerencial nos relatórios de avaliação de desempenho desenvolvidos pelo Escritório Nacional de Auditoria Australiano (Enaa), o qual produz informação no sentido de auxiliar os gestores no planejamento (escolha entre estratégias alternativas), orçamento (justificativa para utilização dos recursos e desenvolvimento de metas de custo), implementação de políticas (confrontação do orçamento realizado com o planejado) e avaliação (assistência na determinação da efetividade do programa e busca por melhores alternativas para seu desenvolvimento). Esses relatórios do Enaa recebem a denominação Relatórios de Auditoria de Eficiência e se preocupam com quatro distintos aspectos, sendo: a) implementação de políticas de avaliação; b) utilização de informações de avaliação no processo orçamentário; c) regras de avaliação para transparência com o parlamento e sociedade civil; e d) impacto da avaliação (Guthrie e English, 1997).

Após mais de 20 anos de aplicação dos princípios da Nova Administração Pública, diversos acadêmicos australianos apontam como positiva a mudança no processo informacional do setor público (Hoque, 2008; Mir e Rahaman, 2007; Hoque e Adams, 2011; Kloot, 2009; Guthrie e English, 1997) e identificam a necessidade de mais estudos aprofundados sobre a 
utilização pelos gestores dos relatórios de desempenho para a tomada de decisão, a fim de identificar quão institucionalizados estão esses procedimentos. Destaque para Hoque e Adams (2011:308), que defendem que a utilização de instrumentos de controle exerce pressão para elevação do desempenho.

Cabe ainda ressaltar que, mediante os estudos apresentados, se percebe claramente que a aplicação da gestão para resultados implica descentralização e desconcentração, onde os gestores recebem seu recurso juntamente com as metas, sendo cobrados pelos resultados; o monitoramento é feito em função da eficácia e efetividade, analisando constantemente a eficiência, fator que reforça para os gestores de todos os níveis a demanda e utilização dos relatórios gerenciais para acompanhamento das realizações e dos gastos. Hoque (2008) informa que o contexto encoraja o desempenho e a flexibilidade em vez de controles rígidos por meio de legislação.

O que a experiência australiana demonstra, conforme Carlin (2003:37), é a necessidade de um amplo debate acerca da adoção de um novo sistema contábil, a elaboração de um arcabouço legal extremamente claro, a preparação do ambiente e a mobilização da burocracia. Sua relação com a teoria institucional se dá justamente na preocupação de que alteradas as normas gerais buscou-se transmitir ao corpo burocrático o entendimento de quão importante seria a incorporação real dos procedimentos e ações preconizados pela Nova Administração Pública para o desenvolvimento do país. Os estudos de Hoque e Adams (2011), Hoque (2008), Herawaty e Hoque (2007), procurando verificar se as entidades governamentais implementaram ferramentas de análise de desempenho contábil e gerencial apenas de modo ritualístico para cumprimento da legislação, encontraram evidências de que o impulso legal é representativo, mas que a incorporação das técnicas ocorreu pelo entendimento dos gestores de que elas elevavam a qualidade das decisões e indica que na visão desses gestores houve melhora da eficiência e efetividade das ações governamentais.

Consultando o relato dos estudos citados é possível dizer que existem evidências de que o processo de alteração do modelo de gestão implementado no setor público australiano não ocorreu apenas por isomorfismo entre as entidades, mas representou uma mudança real no modus operandi do setor público com o estabelecimento de novas instituições.

Cabe por fim destacar que a implementação de um sistema de custeio para o setor público não foi um movimento isolado, mas um processo conjugado a uma grande reforma contábil e institucional.

\section{Avanços recentes da contabilidade pública no Brasil}

Embora a Secretaria do Tesouro Nacional busque uma aproximação das normas internacionais para o setor público, e isso tem sido feito mediante resoluções e decretos, a contabilidade pública brasileira ainda é orientada pela Lei Federal no 4.320/64, que não foi alterada. Essa lei estabelece normas gerais de Orçamento e de Contabilidade Pública, e foi estruturada sobre quatro sistemas de escrituração para que a contabilidade pública pudesse desempenhar seus 
papéis, quais sejam: Sistemas Orçamentário, Financeiro, Patrimonial e de Compensação. Esses sistemas deverão ser alterados para os seguintes subsistemas: Orçamentário, Patrimonial, Custos e Compensação.

No Brasil, atualmente, a contabilidade pública produz informação obedecendo tanto a Lei nํ 4.320/64 quanto as novas orientações da Secretaria do Tesouro Nacional. Seguindo a Lei no 4.320/64, é utilizado no Brasil o regime contábil denominado internacionalmente Regime de Competência Modificado, uma vez que recorre ao regime de caixa para a arrecadação das receitas e ao regime de competência para a realização das despesas. Do ponto de vista internacional ele é classificado como uma variação do regime de competência puro, que é o que deve ser adotado segundo a Secretaria do Tesouro Nacional (STN).

A utilização do regime de competência modificado alcança todos os entes e entidades públicas no Brasil atualmente. Em um país tão grande e composto de diversos entes federados, a opção pela automação da rotina contábil é mais que justificada. Dessa forma, a partir da década de 1980 foi criado o Sistema Integrado de Administração Financeira (Siafi) que, ancorado em um plano de contas, na conta única do tesouro nacional e na tabela de eventos, cumpre as funções de registro, banco de dados, provedor de relatórios contábeis, pagamento e controle.

A introdução do Siafi como ferramenta de auxilio à administração financeira nas entidades públicas representou uma revolução na gestão pública brasileira. Segundo Castro e Garcia (2004:64), antes desse software "o governo não tinha noção dos gastos da Administração Pública, pois se administrava com base na posição do caixa do governo federal controlado em contas bancárias no Banco do Brasil".

O Siafi é uma ferramenta do governo federal e de diversos estados, ${ }^{2}$ desenvolvido pela STN, que agrega os quatro sistemas de escrituração apresentados funcionando dentro do contexto da contabilidade como instrumento de registro e controle. Com ele, os gestores possuem, em tempo real, a posição consolidada das contas governamentais em suas diversas ramificações.

Outro importante avanço que ocorreu em relação às finanças públicas no Brasil remete à introdução da Lei Complementar no 101, de 2000, mais conhecida como Lei de Responsabilidade Fiscal (LRF). Desde 1995 a STN trabalha para ajustar a dívida pública nacional, tendo como premissas: metas de resultados fiscais, limites para endividamento e para gastos com pessoal e limites para investimentos. Tais premissas também representam a plataforma sobre a qual foi elaborada a LRF, que nasceu com o objetivo de estabelecer "normas de finanças públicas voltadas para a responsabilidade na gestão fiscal" (Nascimento e Debus, 2001:5). A LRF é um instrumento em consonância com os novos paradigmas da administração pública, caracterizada pela implementação de funções mais gerenciais e a introdução da participação popular no processo de acompanhamento e fiscalização das contas públicas.

\footnotetext{
${ }^{2}$ Este sistema ainda não foi expandido para os municípios.
} 
As mudanças produzidas pela aplicação da LRF contribuíram para que alguns entes federados impulsionassem o movimento para saneamento das contas públicas e pudessem se preocupar com uma reestruturação mais profunda na capacidade de prestação dos serviços públicos e na promoção do bem-estar social.

A partir de 2007 um novo processo de mudança passou a ser construído para a contabilidade pública brasileira. Por meio da Resolução nº 1.103/07, do Conselho Federal de Contabilidade (CFC), foi criado o Comitê Gestor da Convergência no Brasil, do qual participam, além do CFC, o Banco Central do Brasil (BCB), o Instituto dos Auditores Independentes do Brasil (Ibracon) e a Comissão de Valores Mobiliários (CVM). Esse comitê elaborou o Plano de Ação para convergência do sistema contábil brasileiro às normas internacionais de contabilidade. No plano ficou definido que a convergência para as normas internacionais de contabilidade do setor público ocorreria a partir de 2012 para a União e 2013 para os estados e municípios.

Em 2008 foi editada a Portaria no 184 pelo Ministério da Fazenda, que deu competência à STN para: a) identificar as necessidades de convergência às normas internacionais de contabilidade publicadas pela International Federation of Accoutants (Ifac) e às normas brasileiras editadas pelo CFC; b) editar normativos, manuais, instruções de procedimentos contábeis e Plano de Contas Nacional, objetivando a elaboração e publicação de demonstrações contábeis consolidadas, em consonância com os pronunciamentos da Ifac e com as normas do CFC, aplicadas ao setor público; e c) adotar os procedimentos necessários para atingir os objetivos de convergência estabelecido no âmbito do Comitê Gestor da Convergência no Brasil, instituído pela Resolução CFC no 1.103, de 28 de setembro de 2007.

Já em 2009, o decreto federal no 6.976 estabeleceu o Sistema de Contabilidade Federal e expressou como função deste: (a) identificar as necessidades de convergência aos padrões internacionais de contabilidade aplicados ao setor público; (b) editar normativos, manuais, instruções de procedimentos contábeis e plano de contas aplicado ao setor público, objetivando a elaboração e publicação de demonstrações contábeis consolidadas, em consonância com os padrões internacionais de contabilidade aplicados ao setor público; e (c) adotar os procedimentos necessários para atingir os objetivos de convergência aos padrões internacionais de contabilidade aplicados ao setor público.

Exercendo suas funções, a STN através do SCF e com auxílio do CFC tem divulgado o Manual de Contabilidade Aplicado ao Setor Público. Esse documento faz parte das ações desenvolvidas para padronizar procedimentos de consolidação das contas públicas e apresentar entendimentos gerais sobre os procedimentos contábeis nos três níveis de governo.

Dando início ao processo de convergências das Normas Brasileiras de Contabilidade Aplicadas ao Setor Público (NBCASP) aos padrões internacionais, sob a coordenação do CFC, em 2008 foram aprovadas as primeiras NBCASP que vão orientar a contabilidade aplicada ao setor público, conforme descritas no quadro 3. 
Quadro 3

Normas Brasileiras de Contabilidade Aplicadas ao Setor Público

\begin{tabular}{|clc|}
\hline \multicolumn{1}{|c|}{ Norma } & \multicolumn{1}{c|}{ Descrição } & Resolução do CFC \\
\hline NBC T 16.1 & Conceituação, Objeto e Campo de Aplicação & $1.128 / 2008$ \\
NBC T 16.2 & Patrimônio e Sistemas Contábeis & $1.129 / 2008$ \\
NBC T 16.3 & Planejamento e seus Instrumentos sob o Enfoque Contábil & $1.130 / 2008$ \\
NBC T 16.4 & Transaçães no Setor Público & $1.131 / 2008$ \\
NBC T 16.5 & Registro Contábil & $1.132 / 2008$ \\
NBC T 16.6 & Demonstrações Contábeis & $1.133 / 2008$ \\
NBC T 16.7 & Consolidação das Demonstraç̃̃es Contábeis & $1.134 / 2008$ \\
NBC T 16.8 & Controle Interno & $1.135 / 2008$ \\
NBC T 16.9 & Depreciação, Amortização e Exaustão & $1.136 / 2008$ \\
NBC T 16.10 & Avaliação e Mensuração dos Ativos e Passivos das Entidades do Setor Público & $1.137 / 2008$ \\
\hline
\end{tabular}

Fonte: Elaborado pelo autor.

Esse breve histórico demonstra que a contabilidade pública brasileira ainda possui uma legislação antiga e que a prática contábil encontra-se focada em características orçamentárias e de controle fiscal, mas que, nos últimos anos, tem aberto caminho para uma nova proposta. As mudanças que estão por vir devem provocar uma alteração do sistema contábil como um todo, fato que é defendido por acadêmicos e corroborado pela experiência australiana. Contudo, como será demonstrado, o desenvolvimento pelo governo brasileiro de um sistema de custo não faz parte de uma reforma ampla do sistema contábil e não antecipou as mudanças impostas pela legislação.

\section{Desenvolvimento e implantação do Sistema de Custos no governo federal brasileiro}

A reforma gerencial no Brasil, como já mencionado, teve início no primeiro governo Fernando Henrique Cardoso, com a criação do Mare e a proposição do Plano Diretor da Reforma do Aparelho do Estado (PDRAE). O referido documento foi importante para dar sentido às ações fragmentadas de governo nessa área, mas que, gradativamente, perdeu espaço para as ações de ajuste fiscal (Abrúcio, 2007:77).

Da mesma forma que o PDRAE perdeu força, também o movimento reformista brasileiro não se consolidou como um plano abrangente, de longo prazo e contínuo de governo, capaz de mobilizar toda a administração pública para sua implementação. Conforme Abrúcio (2007:72), alguns pontos que levaram ao fracasso da proposta de reformas do governo 
federal foram: (a) desmantelamento do Estado e o desprestígio do serviço público pela administração central no governo Collor; (b) o histórico recente de reformas administrativas não democráticas; (c) a prevalência da equipe econômica e de seu pensamento na lógica do governo Fernando Henrique Cardoso, o que acabou por subordinar o plano de reformas ao ajuste fiscal; e (d) receio do Legislativo em promover uma reforma em prol da transparência e voltado ao desempenho, pois isso diminuiria a capacidade de a classe política influenciar a gestão dos órgãos públicos.

Todos esses pontos, somados a alguns erros de diagnóstico, tal qual um conceito muito restrito de carreiras estratégicas de Estado, que acabou deixando de fora do núcleo estratégico do governo setores essenciais da União, fundamentais para que ela atue como reguladora, avaliadora e indutora, impediram que fosse desenvolvida uma agenda de forma da gestão pública de caráter transversal, capaz de estabelecer um novo paradigma administrativo no país (Abrúcio, 2007).

O que se percebe no Brasil, desde o enfraquecimento da iniciativa reformista consubstanciada no PDRAE, é a adoção de processos pontuais, fragmentados, promovendo inovações dispersas. As inovações ocorridas foram importantes, contudo sem uma coordenação nacional. Esse parece ser o caso do sistema de custeio do governo federal. Atualmente, como foi descrito, existe um arcabouço legal preparando a convergência da contabilidade pública nacional ao padrão internacional; contudo, o sistema de custeio desenvolvido, como será mostrado, parece não ter se antecipado a essa mudança, valendo-se do sistema contábil atual.

O SIC era gerido, até o final de 2010, pelo secretário executivo do Ministério da Fazenda, Nelson Machado, e a coordenação técnica ficava a cargo de Victor de Holanda. As principais bases teóricas do referido sistema foram as teses de doutorado desses dois gestores, a saber: Sistema de informação de custos: diretrizes para integração ao orçamento público e à contabilidade governamental e Controladoria governamental no contexto do governo eletrônico: uma modelagem utilizando o enfoque sistêmico e a pesquisa-ação na Coordenadoria de Controle Interno da Secretaria da Fazenda do Estado de São Paulo.

Segundo Holanda, Lattman-Weltman e Guimarães (2010:139), o desenvolvimento do SIC estava baseado na premissa de um sistema que não levasse muito tempo para ser implantado. Dessa forma, a plataforma de dados foi definida a partir dos sistemas governamentais já existentes, o já citado Siafi, o Sistema de Informações Gerenciais e de Planejamento (Sigplan) e o Sistema Integrado de Administração de Recursos Humanos (Siape). Os três sistemas, contudo, não foram desenvolvidos para gerarem informações contábeis de custos. O Siafi possui uma ótica orçamentária, apresentando dados de liquidação e pagamento, enquanto o Sigplan possui as informações de execução física e o Siape faz a gestão administrativa e financeira da folha de pagamento. Nada novo foi criado, com os dados extraídos de tais sistemas sendo agrupados em um mesmo banco de dados para assim serem processados.

Soma-se nesse contexto que a previsão legal para o desenvolvimento de um sistema de custos no governo federal brasileiro não é nova, não advém da recente LRF. Ao contrário, 
data de 1964, por meio da Lei no 4.320, cujo art. 85 determina que "os serviços de contabilidade serão organizados de forma a permitirem (...) a determinação dos custos dos serviços industriais". Posteriormente, em 1979, o Decreto-Lei no 200 estabeleceu que "a contabilidade deverá apurar os custos dos serviços de forma a evidenciar os resultados da gestão". Contudo, ficou claro, através dos relatos dos gestores anteriormente citados, que a escolha feita foi pela capacidade de execução imediata, abrindo mão do debate acadêmico acerca de um modelo conceitual de custeio a ser implementado e de uma análise da mudança na estrutura contábil que está por vir, apesar de alguns seminários neste sentido terem sido realizados (Holanda, Lattman-Weltman e Guimarães, 2010:94).

O modelo escolhido prevê o tratamento dos dados extraídos dos sistemas básicos por meio da realização de ajustes contábeis, o que, na visão dos gestores, permite sua transformação em "custos". Esse modelo por ajustes utiliza apenas as informações advindas dos sistemas básicos, sem incorporar estudos sobre depreciação e avaliação patrimonial, que são componentes importantes dos custos. O órgão responsável por determinar os ajustes contábeis a serem realizados é a STN (Holanda, Lattman-Weltman e Guimarães, 2010).

Os gestores argumentam que o modelo desenvolvido pode ser comparado a uma "rodoviária", pois o sistema é amplo e abarca todos os setores da administração pública. Cabe a cada órgão a responsabilidade de aprofundar na alimentação dos dados nos sistemas básicos, melhorando assim a qualidade da informação gerada (Holanda, Lattman-Weltman e Guimarães, 2010:51). Cabe, porém, saber se usam como modelo de rodoviária uma que está dentro de uma metrópole e sem espaço para crescer/implementar suas necessidades, ou uma que utiliza uma visão logística mais avançada e distribui os pontos de atendimento entre as várias regiões da metrópole ou se compara a uma rodoviária de uma metrópole que utiliza, em larga escala, aeroportos, sendo relegado a segundo ou terceiro plano o papel da rodoviária. Porque pensar em uma estrutura que a cada dia perde seu papel por conta das mudanças socioeconômicas pode levar à manutenção do status quo ou mesmo da "velha ordem institucional".

Sob a visão da teoria institucional dificilmente o sistema se tornará uma instituição sem o desenvolvimento de mecanismos de incentivo, formais e informais. Os gestores do SIC entendem que é necessária uma mudança cultural para que o sistema seja incorporado plenamente à gestão pública nacional. Hoje, a maioria dos administradores públicos carece de uma visão clara dos benefícios que um sistema de custos no setor público pode trazer. A expectativa deles é que, se os órgãos de controle e a sociedade civil organizada passarem a verificar as informações disponibilizadas pelo sistema para cobrar ações eficientes dos gestores, acontecerá a mudança cultural esperada. Entretanto, a falta de enforcement por parte da alta gestão do setor público federal enfraquece a utilização do sistema e dificulta a mobilização necessária para tal mudança. Além disso, o SIC foi implementado no último ano de governo do presidente Lula e não se verificou, nos relatos a que se teve acesso, nenhuma determinação legal que tornasse a utilização do sistema obrigatória. 
Quadro 4

\section{Resumo das diferenças na estratégia de implementação do sistema} de custo Austrália $\times$ Brasil

\begin{tabular}{|c|c|c|}
\hline & Austrália & Brasil \\
\hline Escopo & $\begin{array}{l}\text { Abrangente, apropriação de um Movimento de } \\
\text { Reforma mais amplo que o escopo contábil. }\end{array}$ & $\begin{array}{l}\text { Pontual, devido ao enfraquecimento de uma reforma } \\
\text { de caráter mais amplo. }\end{array}$ \\
\hline Planejamento & $\begin{array}{l}\text { Desenvolvimento de um planejamento abrangente } \\
\text { considerando questões técnicas, legais e humanas } \\
\text { no processo. }\end{array}$ & $\begin{array}{l}\text { Desenvolvimento de um planejamento de implemen- } \\
\text { tação do sistema de custos com base no modelo } \\
\text { contábil anterior a alterações legais. }\end{array}$ \\
\hline Mobilização & $\begin{array}{l}\text { Desenvolvimento de plano amplo de capacitação } \\
\text { e de mudança da cultura organizacional. }\end{array}$ & $\begin{array}{l}\text { Capacitação dos setores envolvidos e expectativa de } \\
\text { contaminação pelo uso. }\end{array}$ \\
\hline Envolvimento & $\begin{array}{l}\text { A alta gerência compreende e utiliza os relatórios } \\
\text { gerados para fazer análises das opções e também } \\
\text { avalia os resultados dos gestores a partir das metas } \\
\text { estabelecidas. }\end{array}$ & $\begin{array}{l}\text { Os gerentes públicos não identificam a utilidade } \\
\text { das informações de custos e de desempenho para } \\
\text { tomada de decisão. }\end{array}$ \\
\hline Instituições & $\begin{array}{l}\text { As informações de desempenho fazem parte do dia } \\
\text { a dia dos gestores e estão incorporadas à rotina. }\end{array}$ & $\begin{array}{l}\text { As informações financeiras são estruturadas para } \\
\text { prestação de contas legais principalmente para tri- } \\
\text { bunais de contas. }\end{array}$ \\
\hline Priorização & Qualidade & Tempo \\
\hline $\begin{array}{l}\text { Tecnologia da } \\
\text { Informação }\end{array}$ & $\begin{array}{l}\text { Desenvolvimento de novos sistemas tecnológicos } \\
\text { adaptados a novo padrão. }\end{array}$ & $\begin{array}{l}\text { Desenvolvimento de um novo sistema sobre os } \\
\text { sistemas já existentes. }\end{array}$ \\
\hline
\end{tabular}

Fonte: Elaborado pelo autor.

Para corroborar o argumento institucional de que são necessários outros fatores além do desenvolvimento de uma ferramenta tecnológica para que o sucesso de um processo de mudança cultural se verificasse, segundo Holanda, Lattman-Weltman e Guimarães (2010), nem mesmo os sistemas básicos, que são fonte para o SIC, têm sua utilização incorporada como rotina. Isso ocorre por vários motivos, sendo um dos mais importantes a falta de uma cultura gerencial que priorize a utilização de tais informações para controle e compensação aos indivíduos.

Como se pode perceber pela análise do quadro 3, existe uma grande diferença entre os processos de implementação do sistema de custos dos governos australiano e brasileiro, de onde são originadas as críticas apresentadas sob a ótica institucional.

\section{Considerações finais}

Sob a ótica da teoria institucional pode se considerar a contabilidade gerencial uma instituição, uma vez que ela representa um conjunto de regras capazes de influenciar o comportamento das pessoas, tanto na rotina de preparação dos dados e na produção de informações aos usuários quanto na tomada de decisão. As informações contábeis gerenciais são utiliza- 
das para controle, avaliação e compensação no setor privado e também para os governos e órgãos públicos.

A administração pública, de forma geral, sempre utilizou informações oriundas da contabilidade para a gestão da coisa pública. Muitas vezes, como é o caso brasileiro, essa análise possui um foco orçamentário. Contudo, a partir das reformas governamentais que tiveram início na década de 1970, foi introduzida uma nova visão e cultura no setor público, associada à Nova Gestão Pública, a qual defende ações voltadas para resultados, enfatizando a eficiência e buscando uma maior autonomia e responsabilização através da descentralização dos controles gerenciais.

Esse novo modelo de gestão é balizado pela construção de indicadores de desempenho, muitos deles originários na contabilidade, dos quais o indicador custo está entre os mais importantes. Assim, para melhor atender às demandas de indicadores os países que implementaram reformas gerenciais afinadas com a nova gestão pública também reformularam seus sistemas de contabilidade para permitir que informações como as de custos dos serviços e políticas públicas pudessem ser produzidas. Um exemplo, mobilizado no artigo, é o caso australiano, onde houve a compreensão de que uma mudança dessa magnitude perpassa todos os níveis da administração pública e é preciso embasamento teórico e legal, além da aceitação institucional para que ela aconteça.

É sobre essa visão que se ancora o argumento de Diamond (2002), segundo o qual o aproveitamento de todas as vantagens de uma reforma no regime de contabilidade requer uma mudança fundamental na forma de administrar o setor público e na gestão de recursos humanos desse setor, com o intuito de fortalecer a transparência e a responsabilização. Na mesma direção, a OECD (1993:13) argumenta que

A introdução do regime de competência implica a adoção de substanciais investimentos em sistemas de informações gerenciais com o objetivo de dar suporte na elaboração dos orçamentos e na melhoria das práticas administrativas. Ela requer uma mudança cultural nas instituições através do entendimento e aceitação de como utilizar as informações adicionais e os potenciais benefícios que podem ser produzidos, com o comprometimento com a mudança.

É pertinente ampliar a discussão do ambiente organizacional neste ponto, pois diante de mudanças tão significativas fica subentendido que condições mínimas de desenvolvimento humano são exigidas. Para Diamond (2002), a mudança ambiental mais profunda e revolucionária seria a adaptação das políticas de pessoal do setor público. Todas as alterações no modelo de gestão do governo irão exigir novas habilidades dos funcionários. Dessa forma, novas regras de mobilidade e remuneração deverão ser adotadas para criar incentivos ao trabalho eficiente. Os órgãos serão cobrados por seus produtos e resultados, o que consequentemente será transferido para os colaboradores. Assim, esses últimos precisam de motivação e conhecimento claro de como seu trabalho impactará no resultado de todo o governo.

Tal fato, em consonância com a literatura, acaba por despertar debates sobre a relevância da adoção de reformas amplas, buscando não apenas alterações focadas, mas reformas transversais que levem em conta questões ambientais, de recursos humanos e legais. 
A reforma da administração pública brasileira no nível federal não amadureceu o suficiente para adquirir um caráter contínuo e transversal, acontecendo pontualmente em órgãos dispersos. Ao longo dos últimos 15 anos várias iniciativas têm surgido, esbarrando sempre em questões estruturais, tal qual resistência do sistema político, uma mudança cultural contra o patrimonialismo e a necessidade de uma visão integrada e de longo prazo da gestão pública que mobilize as ações dos servidores públicos (Abrúcio, 2007).

O SIC se enquadra nesse contexto, constituindo uma ferramenta que se propõe a cumprir um papel dinamizador para a mudança cultural esperada. A proposta é de um sistema que permita a todos os órgãos da administração pública federal produzir, para seus gestores e para a sociedade, informações referentes aos custos de seus projetos, serviços e políticas públicas. Assim, sua utilização faria (espera-se) com que a população fiscalizasse o governo por meio dos relatórios disponíveis, o que obrigaria os servidores a serem mais criteriosos na entrada dos dados no sistema. Contudo, o SIC teve, como premissa básica, o tempo necessário para sua implantação, negligenciando o processo de convergência às normas internacionais de contabilidade do setor público que o país iniciará em 2012 e o debate acerca do método de custeio mais adequado a ser aplicado na administração pública.

Além disso, o processo de implantação, sob uma ótica institucionalista, carece de uma ação mais efusiva e contundente da alta administração do governo federal, de um modelo legal e de ações de conscientização nos demais níveis da hierarquia governamental.

O que se propôs neste artigo é uma discussão sobre institucionalismo e as mudanças na contabilidade gerencial, tentando contextualizar as ações do governo brasileiro contrapondoas à experiência internacional. Cabe ressaltar que a implementação do SIC é muito recente e necessita de avaliações, após um período de maturação, para confrontar os acontecimentos com os pressupostos da teoria institucional. Abre-se espaço também para estudos de como a alteração dos padrões contábeis do setor público pode contribuir para a mudança cultural necessária para uma visão mais eficiente da gestão pública.

\section{Referências}

ABRÚCIO, Fernando L. Trajetória recente da gestão pública brasileira: um balanço crítico e a renovação da agenda de reformas. Revista de Administração Pública, Edição Especial Comemorativa, p. 67-86, 2007.

ALONSO, Marcos. Custos no Serviço Público. Revista do Serviço Público, ano 50, n. 1, p. 37-63, 1999.

BOLAND, Tony; FOWLER, Alan. A systems perspective of performance management in public sector organizations. The International Journal of Public Sector Management, v. 13, n. 5, p. 417-446, 2000.

BRASIL. Decreto ํㅜ 6.976, de 7 de outubro de 2009. Diário Oficial [da] República Federativa do Brasil, Poder Executivo, Brasília, DF, 8 out. 2009. 
BRASIL. Decreto-Lei no 200, de 25 de fevereiro de 1967. Diário Oficial [da] República Federativa do Brasil, Poder Executivo, Brasília, DF, 27 fev. 1967.

BRASIL. Lei 4.320 de 17 de março de 1964. Institui normas gerais de direito financeiro para elaboração e controle dos orçamentos e balanços da União, dos estados, dos municípios e do Distrito Federal. Disponível em: <www.planalto.gov.br/ccivil_03/leis/L4320.htm>. Acesso em: 19 out. 2010.

BRASIL. Lei Complementar no 101, de 4 de maio de 2000. Diário Oficial [da] República Federativa do Brasil, Poder Executivo, Brasília, DF, 5 maio 2000.

BRESSER-PEREIRA, Luis C.; SPINK, Peter K. (Org.). Reforma do Estado e administração pública gerencial. Rio de Janeiro: Editora Fundação Getulio Vargas, 1998.

BURNS, John; SCAPENS, Robert W. Conceptualizing management accounting change: an institutional framework. Management Accounting Research, v. 11, p. 3-25, 2000.

CARLIN, Tyrone M. Accrual accounting e financial reporting in the public sector: reframing the debate. MGSM Working Papers in Management, Sydney, n. 22, 2003.

CASTRO, Domingos P.; GARCIA, Leice M. Contabilidade pública no governo federal. São Paulo: Atlas, 2004.

DIAMOND, Jack. Performance budgeting: is accrual accounting required? IMF Working Paper, 2002. Disponível em: <www.blackwellpublishing.com> Acesso em: out. 2008.

FRANCESCO, Michael D. Measuring performance in policy advice output. The International Journal of Public Sector Management, v. 12, n. 5, p. 420-431, 1999.

FRANCO, Raquel A. Planejamento público no estado de Minas Gerais: uma trajetória no Estado de Minas Gerais. 2004. Monografia (graduação em administração pública) — Escola de Governo Professor Paulo Neves de Carvalho, Fundação João Pinheiro, Belo Horizonte, 2004.

GIDDENS, Anthony. The constitution of society. Cambridge: Polity Press, 1984.

GUERREIRO, Reinaldo et al. O entendimento da contabilidade gerencial sob a ótica da teoria institucional. o\&s, v. 12, n. 35, p. 92-106, 2005.

GUTHRIE, James. Application of accrual accounting in the Australian public sector: rhetoric or reality? Financial Accountability e Management, v. 14, n. 1, p. 1-19, 1998. Disponível em: <www. blackwellpublishing.com>. Acesso em: out. 2008.

GUTHRIE, James; ENGLISH, L. Performance information and programme evaluation in the Australian public sector. International Journal of Public Sector Management, v. 10, n. 3, p. 154-164, 1997.

GUTHRIE, James; OLSON, Olov; HUMPHREY, Christopher. Debating developments in New Public Financial Management: the limits of global theorising and somo new ways forward. Financial Accountability e Management, v. 15, n. 3, p. 209-228, 1999.

HERAWATY, Merry; HOQUE, Zahirul. Disclosure in the annual reports of Australian government departments: a research note. Journal of Accounting \& Organizational Change, v. 3 n. 2, p.147-168, 2007. 
HODGKINSON, Ann. Productivity measurement and enterprise bargaining - the local government perspective. The International Journal of Public Sector Management, v. 12, n. 6, p. 470-481, 1999.

HOLANDA, Victor B.; LATTMAN-WELTMAN, Fernando; GUIMARÃES, Fabrícia (Org.). Sistema de informação de custos na administração pública federal: uma política de Estado. Rio de Janeiro: Editora FGV, 2010.

HOQUE, Zahirul. Measuring anda reporting public sector outputs/outcomes: exploratory evidence from Australia. International Journal of Public Sector Management, v. 21, n. 5, p. 468-493, 2008.

HOQUE, Zahirul; ADAMS, Carol. The rise and use of Balanced Scorecard Measure in Australian goverment departaments. Financial Accountability e Management, v. 27, n. 3, p. 308-334, 2011.

IFAC. International Federation of Accoutants. Government financial reporting: accounting issues and practices. 2000, Study 11. Disponível em: <www.ifac.org > . Acesso em: set. 2010.

IUDÍCIBUS, Sergio; MARION, José C. Dicionário de termos de contabilidade. São Paulo: Atlas, 2001.

KLOOT, Louise. Performance measurement and accountability in an Australian fire service. International Journal of Public Sector Management, v. 22, n. 2, 2009. Disponível em: <www.emeraldinsight. com/09-3558.htm>. Acesso em: jan. 2012.

MACHADO, Nelson; HOLANDA, Victor B. Diretrizes e modelo conceitual de custos para o setor público a partir da experiência no governo federal do Brasil. Revista de Administração Pública, v. 44, n. 4, p. 791-820, 2010.

MARTINS, Eliseu. Contabilidade de custos. São Paulo: Atlas, 2006.

MARTINS, Gilberto A.; THEOPHILO, Carlos R. Metodologia da investigação científica para ciências sociais aplicadas. São Paulo: Atlas, 2007.

MIR, Monir Z.; RAHAMAN, Abu S. Accounting and public sector reforms: a study of a continuously evolving governmental agency in Australia. Accounting, Auditing e Accountability Journal, v. 20, n. 2, p. 237-268 2007. Disponível em: <www.emeraldinsight.com/0951-3574.htm>. Acesso em: 21 fev. 2012.

NASCIMENTO, Edson R.; DEBUS, Ilvo. Entendendo a lei de responsabilidade fiscal. Brasília, 2001. Disponível em: <www.spadm.com.br/download/arquivos/entendendoalei.pdf>. Acesso em: maio 2009.

NORTH, Douglass C. Institutions, institutional change and economic performance. Cambridge: Cambridge University Press, 1990.

OECD. Organisation for Economic Co-operation and Development. Accounting for what? The value of accrual accounting to the public sector. Paris: OECD, 1993.

POWELL, Walter W.; DIMAGGIO, Paul J. The new institutionalism in organizational analysis. Chicago: The University of Chicago Press, 1991. 
REZENDE, Fernando; CUNHA, Armando; BEVILACQUA, Roberto. Informações de custos e qualidade do gasto público: lições da experiência internacional. Revista de Administração Pública, v. 44, n. 4, p. 959-992, 2010.

REZENDE, Flávio C. As reformas e as transformações no papel do Estado: o Brasil em perspectiva comparada. In: ABRÚCIO, Fernando Luiz; LOUREIRO, Maria Rita (Org.). O Estado em uma era de reformas: os anos FHC. Belo Horizonte; Brasília: MP, SEGES, 2002. Parte 1, p. 163-207.

WARREN, Ken.; BARNES, Cheryl. The impact of Gaap on fiscal decision making: a review of twelve yerars' experience with accrual and output-based budgets in new zealand. OECD Journal on Budgeting, v. 3, n. 4, p. 7-40, 2003. Disponível em: <www.blackwellpublishing.com>. Acesso em: out. 2008.

Thiago Bernardo Borges é professor no Instituto Brasileiro de Mercado de Capitais (IBMEC-MG), mestre em ciências contábeis pela Universidade Federal de Minas Gerais (UFMG), empreendedor público no Gabinete de Secretário de Estado Extraordinário da Copa do Mundo de Minas Gerais. E-mail: Thiago. borges@copa.mg.gov.br

Poueri do Carmo Mario é doutor e mestre em ciências contábeis pela Faculdade de Economia e Administração da Universidade de São Paulo (FEA/USP), professor do Instituto Brasileiro de Mercado de Capitais (IBMEC-MG) e professor adjunto do mestrado em ciências contábeis da Faculdade de Ciências Econômicas da Universidade Federal de Minas Gerais (UFMG). E-mail: poueri@face.ufmg.br

Ricardo Carneiro é doutor em ciências humanas: sociologia e política pela Universidade Federal de Minas Gerais (UFMG), professor na Escola de Governo Professor Paulo Neves de Carvalho da Fundação João Pinheiro. E-mail: Ricardo.carneiro@fjp.mg.gov.br. 